\title{
Determinação, Separação e Produção de Substâncias Orgânicas Através de Métodos Ópticos
}

\author{
Susana Costa Calmon \\ Instituto de Química, Universidade Federal da Bahia, Campus de Ondina, Salvador - BA - Brasil, CEP 40170-290 \\ (???@ufba.br)
}

\section{Objetivo}

Mostrar o potencial tecnológico a partir da análise do número de patentes depositadas que utilizam métodos ópticos com a finalidade de determinação, separação ou produção de substâncias orgânicas.

\section{Aspectos tecnológicos}

Medidas baseadas em luz e outras formas de radiação eletromagnética baseiam-se na medida da quantidade de radiação produzida ou absorvida pelas moléculas ou pelas espécies atômicas de interesse

A espectroscopia desempenhou um papel fundamental no desenvolvimento da teoria atômica moderna. Tem provido ferramentas importantes para elucidação de estruturas moleculares e determinação qualitativa e quantitativa de compostos orgânicos e inorgânicos

A amostra é excitada aplicando-se energia na forma de calor, energia elétrica, luz, partículas ou por uma reação química. Mede-se a radiação eletromagnética emitida quando a amostra retorna ao estado fundamental, ou a quantidade absorvida, decorrente da excitação.

\section{Escopo}

Foi utilizada a palavra-chave optic* e o código de classificação internacional C07B63 no banco de dados Espacenet, sendo encontradas 159 patentes em setembro de 2007.

Tabela de pesquisa por palavras-chave e código de classificação internacional

\begin{tabular}{ll}
\hline Palavras-chave e códigos & EP \\
\hline laser* and C07G & 3 \\
laser* and C07B & 76 \\
C07B63 & 8494 \\
laser* and C07B63 & 5 \\
identificat and C07B57 & 9 \\
identificat and C07G & 27 \\
metod* otic* & 101 \\
otic* and C07B & 2 \\
optic* and C07B63 & 159 \\
\hline
\end{tabular}




\section{Resultados e Discussão}

1. Evolução Anual de Depósitos de Patentes

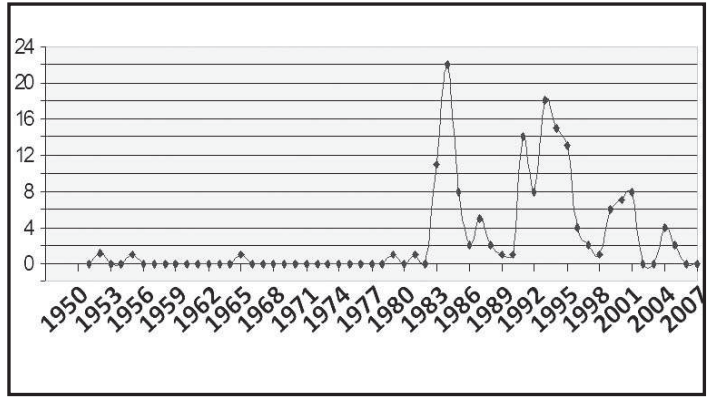

2. Patentes por País/Organização

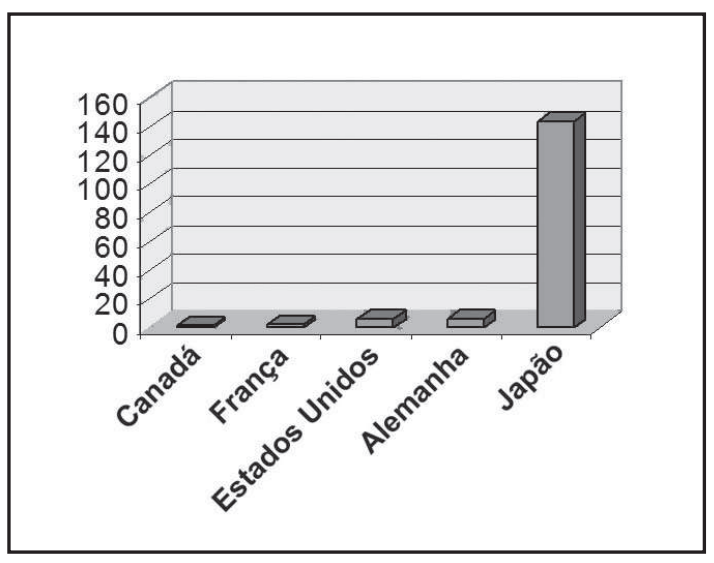

\section{Patentes por Principais Inventores}

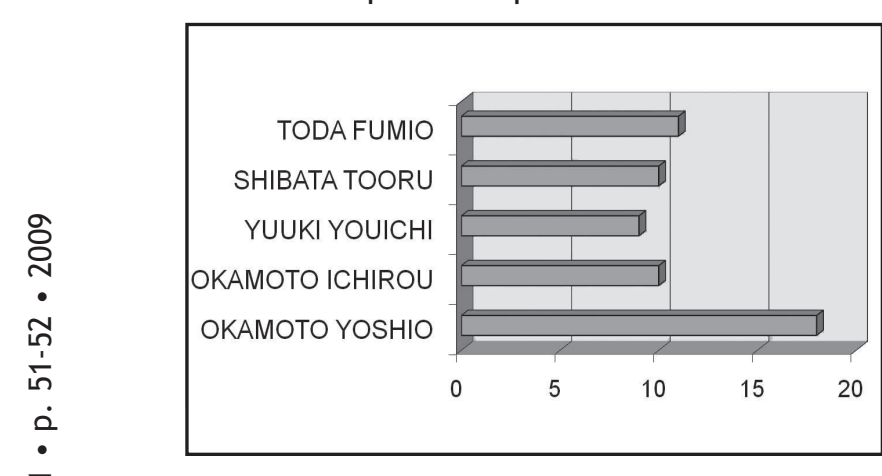

\section{Patentes por Empresa}

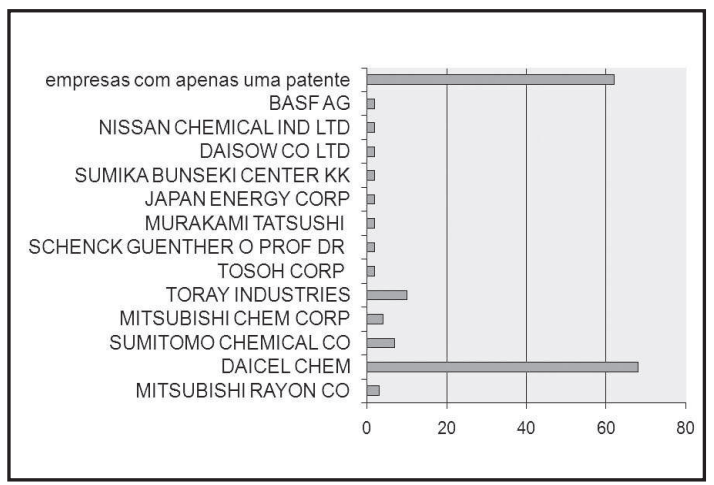

\section{Distribuição por código}

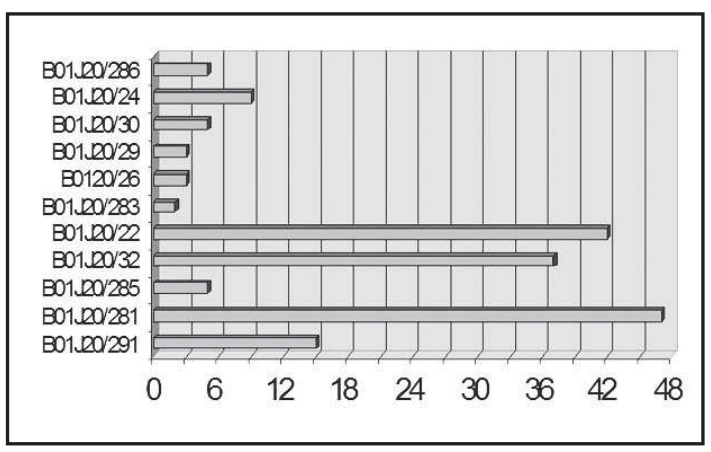

B01J20 - Processos químicos ou físicos,por ex: catalise química coloidal; aparelhos pertinentes aos mesmos como sorventes composições auxiliares para filtração

/30 - para preparo, regeneração ou reativação

/26 - compostos macromoleculares sintéticos

/22 - compreendendo material orgânico

/32 - impregnação ou revestimento

/24 - compostos macromoleculares de ocorrência natural por ex: ácido húmicos ou seus derivados.

6. Distribuição por instituição

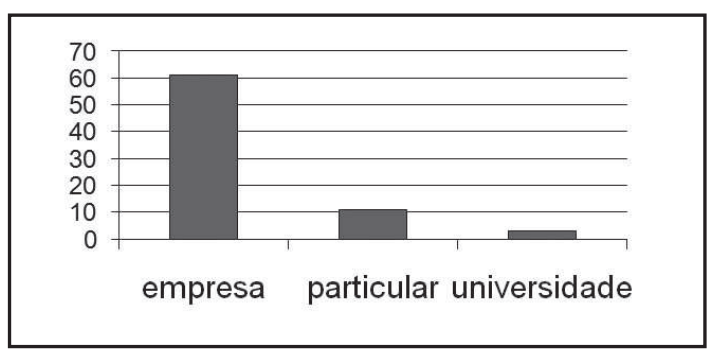

O Japão é o país que mais produziu patentes nesta área nos últimos anos e esse fato pode ser devido a incentivos do governo em pesquisas como, por exemplo, a redução do impostos para depósito de patentes no país. Empresas privadas ainda são as que mais depositam patentes nesta área e um dos objetivos pode ser a exportação dessa tecnologia para paises emergentes que ainda não a desenvolveram, mas necessitam utilizála. Dentre as empresas que mais depositam patentes, na área de métodos ópticos, estão as de química e isso pode ser devido a uma necessidade direta e/ou para a comercialização dessa tecnologia.

Susana Costa Calmon é aluna de graduação em Engenharia Química da UFBA e aluna de Iniciação Científica no LabLaser do Instituto de Química da UFBA. Este trabalho foi realizado no semestre de 2007.2 durante a disciplina optativa "Marcas, Patentes e Propriedade Industrial" ministrada pela Prof $^{a}$. Cristina M. Quintella. Não tinha tido contato anterior com o tema. 